\section{Effects of colchicine on risk of cardiovascular events and mortality among patients with gout: the effect of index date selection?}

We read with great interest the study by Solomon $e t ~ a l^{1}$ regarding the effect of colchicine on risk of cardiovascular (CV) events and all-cause mortality. In their study, they report a marked reduction in the number of $\mathrm{CV}$ events and all-cause mortality with the use of colchicine when compared with a reference group not using this drug. Sensitivity analyses mimicking an intention to treat approach showed similar results. Interestingly, no clear gradient of effect according to duration of use was found. The striking protective effect and the limited evidence for a causal relationship raised some questions regarding methodological aspects of this study that we feel warrants further discussion.

We agree with the authors that the non-users may have been sicker despite similar baseline characteristics, and therefore did not receive colchicine. We would like to propose an extension to this theory. As described in the methods section, non-users were matched by age, gender and index date. In order to minimise selection bias, a non-user is usually assigned the index date of his matched exposed patient. ${ }^{2}{ }^{3}$ While this was the case in this study, an additional condition for the non-user (control) index date was required. In order to be eligible for matching, non-users had to have a Medicare visit, which could include hospitalisations or physician visits, on the same day as the colchicine user index date. This would entail that patients who were eligible to be matched were not average patients, but those who had a reason to visit a physician. Inherently, the non-users were then likely to have an illness (ie, reason to visit the physician) on or close to the index date. Moreover, if the visit was for, or associated with, one of the CV outcomes, this could have led to the selection of a high-risk reference group. If this were true we would expect higher rates of $\mathrm{CV}$ outcomes among the control patients immediately following the index date, with a waning of risk during follow-up. Indeed this is what is suggested by the results in this study, and particularly in the sensitivity analysis, where control patients with a physician visit, which was interpreted as the index date, are more likely to experience the outcome shortly after the index date rather than later. Perhaps excluding patients with visits related to the outcomes, or assigning control patients a random index date (ie, incident density sampling), would help mediate concerns of a sicker control group.

Johannes TH Nielen, ${ }^{1,2}$ Olorunfemi Oshagbemi, ${ }^{1,2}$ Frank de Vries, ${ }^{1,2}$ Andrea M Burden ${ }^{1,2}$

'Department of Epidemiology, Care and Public Health Research Institute (CAPHRI), Maastricht University, Maastricht, The Netherlands

${ }^{2}$ Department of Clinical Pharmacy and Toxicology, Maastricht University Medical Center +, Maastricht, The Netherlands

Correspondence to Johannes TH Nielen, Maastricht University, P.O. Box 616, 6200 MD Maastricht, The Netherlands; yannick.nielen@mumc.nl

Competing interests None declared.

Provenance and peer review Not commissioned; internally peer reviewed.

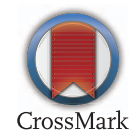

To cite Nielen JTH, Oshagbemi O, de Vries F, et al. Ann Rheum Dis 2016;75:e26.

Received 19 January 2016

Accepted 21 January 2016

Published Online First 12 February 2016

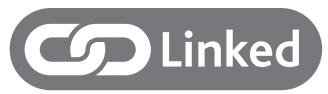

http://dx.doi.org/10.1136/annrheumdis-2016-209242

Ann Rheum Dis 2016;75:e26. doi:10.1136/annrheumdis-2016-209224

\section{REFERENCES}

1 Solomon DH, Liu CC, Kuo IH, et al. Effects of colchicine on risk of cardiovascular events and mortality among patients with gout: a cohort study using electronic medical records linked with Medicare claims. Ann Rheum Dis Published Online First 18 Nov 2015. doi:10.1136/annrheumdis-2015-207984

2 Knapen LM, van Dalem J, Keulemans YC, et al. Use of incretin agents and risk of pancreatic cancer: a population-based cohort study. Diabetes Obes Metab 2015. Published Online First 8 Jan 2016.

3 Essers I, Stolwijk C, Boonen A, et al. Ankylosing spondylitis and risk of ischaemic heart disease: a population-based cohort study. Ann Rheum Dis 2016;75:203-9. 